\section{Use of Trinexepac-ethyl for Growth Regulation of Chrysanthemum (Dendranthema $\times$ grandiflora)}

\author{
D.S. Gardner ${ }^{1}$ and J.D. Metzger ${ }^{2}$ \\ Department of Horticulture and Crop Science, 2001 Fyffect Road, The Ohio \\ State University, Columbus, OH 43210-1086
}

Additional index words. gibberellins, PGR, growth retardant, Primo

Abstract. Trinexapac-ethyl(TE) [4-(cyclopropyl- $\alpha$-hydroxy-methylene)-3, 5-dioxocyclohexanecarboxylic acid ethyl ester] is a plant growth regulator registered for use in turfgrass. The objective of the research reported in this paper was to determine if TE could be used in the production of florist chrysanthemums (Dendranthema $\times$ grandiflora) to produce more compact, higher value plants. Foliar applications of TE to non-pinched plants of the tall cultivar 'Billings' reduced canopy height $8 \%$ to $40 \%$ as the amount of applied TE was increased from $6.25 \times 10^{-5}$ to $2.0 \times 10^{-3} \mathrm{~g}$. The effects of TE varied among chrysanthemum cultivars. Growth inhibition of pinched plants among the various cultivars ranged from $\mathbf{7 \%}$ ('White Viewtime') to $23 \%$ ('White Graceland') 28 days following a single application of $1.0 \times 10^{-3} \mathrm{~g}$ TE. In most cultivars, the inhibitory action of TE was not observed after 28 days. In fact some cultivars exhibited a rebound effect during the post-suppression growth phase in which internode extension rates were greater in TE-treated plants than controls. Both the number and timing of the TE application affected efficacy. A second TE application 5 weeks after the first treatment, or application of TE at the appearance of flower buds produced the highest quality crop in terms of uniformity and compactness, with overall height reduction generally $15 \%$ to $20 \%$. No differences in flower color, number, or mass per flower were observed due to TE application.

Plant growth regulators (PGRs) are used in the production of container-grown herbaceous ornamentals to control stem elongation and produce more compact plants, resulting in a higher quality appearance (Nelson, 1998). Most PGRs used for this purpose are inhibitors of gibberellin (GA) biosynthesis (Nelson, 1998). Of commercial PGRs with this mode of action, there are three different classes that target different enzymes in the GAbiosynthetic pathway. Onium-type compounds such as chlomequat chloride [(2-chloroethyl)-trimethyl ammonium chloride] and mepiquat chloride (1, 1 dimethylpiperidinium chloride) typically block the formation of ent-kaurene, a very early step in the GA biosynthetic pathway. A second group is the nitrogen-containing heterocycles; these compounds inhibit monoxygenases that sequentially oxidize ent-kaurene to ent-kaurenoic acid. Examples of this class commonly used in the production of ornamentals include ancymidol [ $\alpha$-chloropropyl-(p-methoxyphenyl)-5pyrimidinemethanol], paclobutralzol [ $(2 R S$, $3 R S)$-1-(4-chlorophenyl)-4,4-dimethyl-2-(1H1,2,4-triazol-1-yl) pentan-3-ol], flurprimidol

Received for publication 5 Aug. 2004. Accepted for publication 20 Sept. 2004. Salaries and research support provided in part by State and Federal funds appropriated to the Ohio Agricultural Research and Development Center, The Ohio State University. Journal article HCS-03-38. We thank Yoder Brothers, Inc. for their generous donation of chrysanthemum cuttings. We also thank the OSU H\&CS greenhouse staff for their assistance in maintaining the trials. ${ }^{1}$ Assistant professor of turfgrass science. To whom requests for reprints should be addressed; e-mail gardner.254@osu.edu.

${ }^{2}$ Professor of plant physiology. $\{\alpha-(1-m e t h y l)-[p-4-(t r i f l u o r o m e t h o x y) p h e n$ yl]-5-pyrimidinemethanol $\}$, and uniconazole [(E)- $(R S)$-1-(chlorophenyl)4,4-dimethyl2-(1H-1,2,4-triazol-1-yl)]. A third group of PGRs inhibit the soluble oxygenases that require 2-oxoglutaric acid as a cofactor. These enzymes are responsible for the conversion of gibberellin $A_{12}\left(G A_{12}\right)$-aldehyde to GAs with intrinsic biological activity such as $\mathrm{GA}_{4}$ and $\mathrm{GA}_{1}$. Since these compounds are structural mimics of 2-oxogluataric acid they are thought to act by competing for the co-factor binding site. Examples include daminozide (succinic acid 2,2-dimethyl hydrazide) and the two acylcyclohexanediones, prohexadione-calcium (calcium 3-oxido-4-propionyl-5-oxo-3-cyclohexenecarboxylate) and trinexapac-ethyl (TE) [4-(cyclopropyl- $\alpha$-hydroxy-methylene)-3,5 dioxocyclo-hexanecarboxylic acid ethyl ester] (Rademacher, 2000). Columbus, Ohio, in 2002 and 2003.
This latter compound was introduced for use in turfgrass in 1991 (Lickfeldt et al., 2001). Suppression of turfgrass growth under field conditions using TE can exceed $40 \%$ for 4 to 5 weeks after application (Daniels and Sugden, 1996; Fagerness and Penner, 1998; Fagerness and Yelverton, 2000). While the effects of TE on turfgrass have been well studied, this is not the case for herbaceous ornamentals. The objective of the research reported herein was to investigate whether a commercial formulation of TE used in turfgrass could also be used as a growth regulator in floriculture crops. We chose the florist chrysanthemum, Dendranthema $\times$ grandiflora, inasmuch as growth regulators are heavily used in the production of this important floriculture crop (Nelson, 1998)

\section{Materials and Methods}

Plant culture and chemical treatments. In all experiments, four rooted cuttings of Dendranthema $\times$ grandiflora (Yoder Bros., Barberton, Ohio) were transplanted into 10 $\times 10-\mathrm{cm}$ plastic pots filled with a peat-based soilless medium (Metro-Mix 360; The Scotts Co., Marysville, Ohio). The experiments were conducted on cultivars with different height and flowering characteristics in order to determine if the response to TE could be generalized or if it was cultivar specific (Table 1). All plants were grown in a glass greenhouse at The Ohio State University, Columbus, Ohio, with a constant set point temperature of $21^{\circ} \mathrm{C}$ and pots were irrigated as needed. All plants in the experiments were fertilized three times per week using Peter's 20N-4.3P-16.6K Peat-lite special (The Scotts Co.) at $200 \mathrm{mg} \mathrm{N} / \mathrm{L}$.

Plants were treated with TE (Primo 1EC, Syngenta Crop Protection Corp., Greensboro, $\mathrm{NC}$ ) as a spray to the foliage 11 to $12 \mathrm{~d}$ after planting. A hand held sprayer (model LV-32; Sprayco, Inc., Detroit, Mich.) was used. The sprayer was calibrated to deliver $4.2 \mathrm{~mL}$ of solution for each five full depressions of the trigger mechanism. The spray volume was monitored by spraying into a $10-\mathrm{mL}$ Erlenmeyer flask before TE application and after application to every three pots. The mean spray volume per pot throughout the experiments was 4.2 $\mathrm{mL}$ with a standard deviation of $0.1 \mathrm{~mL}$. Each concentration of TE was made separately.

In the dose response study a drench applica-

Table 1. Production characteristics of chrysanthemum cultivars used in trinexapac-ethyl experiments in

\begin{tabular}{lcccc}
\hline Cultivar & $\begin{array}{c}\text { Flower } \\
\text { color }\end{array}$ & Ht & Timing & $\begin{array}{c}\text { Experiments } \\
\text { used }\end{array}$ \\
\hline Billings & White & Tall & 8 & Dose response \\
Chesapeake & Yellow & Medium & 8 & Repeat application \\
Gainesville & White & Medium & 8 & Cultivar response \\
Miramar & Yellow & Medium & 9 & Cultivar response, flowering \\
Sandusky & Yellow & Medium & 8 & Cultivar response, flowering \\
Surf & White & Medium & 8 & Repeat application \\
Vyron & Yellow & Tall & 9 & Cultivar response \\
White Blush & White & Short & 8 & Repeat application \\
White Davis & White & Medium & 9 & Cultivar response \\
White Graceland & White & Tall & 8 & Cultivar response \\
White Viewtime & White & Tall & 9 & Cultivar response \\
Yellow Nob Hill & Yellow & Tall & 10 & Repeat application \\
Yellow Snowdon & Yellow & Tall & 8 & Cultivar response \\
\hline
\end{tabular}

${ }^{\mathrm{z}}$ Average number of weeks after transplant of plugs required to finish crop. 
tion was made to half of the pots by spraying the soil surface with $4.2 \mathrm{~mL}$ of TE solution immediately followed by addition of $100 \mathrm{~mL}$ of water. In all experiments except the dose response study, plants were pinched 13 to 14 $\mathrm{d}$ after planting by removing about $2.5 \mathrm{~cm}$ of the shoot tip.

Dose response study. Experiments were initiated on 27 June 2002 and 6 Jan. 2003 using 'Billings', which is a tall cultivar (Table 1). For the first experiment, no shade cloth or night interruption lighting was used. In the second experiment, night interruption lighting was used until 17 Feb. 2003 to suppress flowering. This was accomplished by providing 100 $\mu \mathrm{mol} \cdot \mathrm{m}^{-2} \cdot \mathrm{s}^{-1}$ photosynthetically active radiation at bench level from with 1000-W Agrosun metal halide lamps (Hydrofarm, Inc., Petaluma, Calif.) from 2200 to $0200 \mathrm{HR}$. Each of the four plants in each pot were treated with $6.25 \times 10^{-5}$, $1.25 \times 10^{-4}, 2.50 \times 10^{-4}, 5.0 \times 10^{-4}, 1.0 \times 10^{-3}$, or $2.0 \times 10^{-3} \mathrm{~g}$ of TE on 9 July 2002 and 17 Jan. 2003 in the first and second experiments, respectively. For each plant the height from the soil surface to the apical meristem was measured and number of nodes was counted each week for 6 weeks.

Cultivar response study. A cultivar response experiment involving eight cultivars (Table 1) was initiated on 27 June 2002 and repeated on 18 Feb. 2003. For the first experiment, plants were covered with black cloth starting on 27 June 2002 until flower buds were visible 5 weeks later. For the second experiment, no night interruption lighting or black cloth was used.

On 9 July 2002 (first experiment) and 3 Mar. 2003 (second experiment) each plant from each cultivar was treated with $0,5.0 \times 10^{-4}$, or 1.0 $\times 10^{-3} \mathrm{~g}$ of TE. The canopy height of the four plants in each pot was determined after 28 and $42 \mathrm{~d}$ by placing a ruler on the surface of the medium in the center of the pot and measuring the highest point of the canopy.

Repeat application study. Experiments were initiated on 6 Jan. and 21 Feb. 2003. In the first experiment plants were maintained vegetative for 6 weeks using night interruption lighting. For the second study, no night interruption lighting was used. In the first experiment, plants were treated with 0 , or $5.0 \times 10^{-4} \mathrm{~g}$ of TE on 17 Jan. 2003. A group TE-treated plants received a second application of $5.0 \times 10^{-4} \mathrm{~g}$ TE on $21 \mathrm{Feb} .2003$. In the second experiment plants were treated on 5 Mar. and 9 Apr. 2003. Canopy height for each pot was determined 28 , 42 , and $63 \mathrm{~d}$ after the first treatment.

Effect on flowering study. An experiment to evaluate the effects of TE on flower development was initiated on 7 Jan. 2002. Plants were maintained vegetative for 6 weeks using night interruption lighting and were then induced to flower by natural photoperiods. Plants were treated with $4.0 \times 10^{-3} \mathrm{~g}$ ofTE either when flower buds were visible (3 Mar. 2003), or at bud break (21 Mar. 2003). In the second experiment, plants were placed in inductive photoperiods when the rooted cuttings were planted (3 Mar. 2003). As in the first experiment TE $\left(4.0 \times 10^{-3} \mathrm{~g} / \mathrm{plant}\right)$ was applied at visible bud (16Apr. 2003) or bud break (30 Apr. 2003). Data on canopy height, number of flowers and total flower weight were collected and mean mass per flower was determined for each cultivar.

Statistical analysis. All experiments were arranged in a randomized complete block design with three replications. There were three replicate pots containing four plants per treatment. For each of the four studies, the results of the two separate experiments were combined. The data of all experiments are expressed as the effect of TE dosage applied to individual plants, except in the dose response experiment in which data are expressed as the effect of total TE dose applied to an individual pot. For the dose response study, response means were regressed on the log-transformed TE doses using the PROC REG procedure of SAS (SAS Institute, 1990). Data from the remaining studies were analyzed using the General Linear Models procedure of SAS. Data are presented as means and standard deviations of the dose $\times$ cultivar or dose $\times$ application schedule interaction.

\section{Results}

Dose response study. Both foliar and drench applications of TE resulted in a log-linear decrease in plant height as amount of applied TE increased, although foliar application resulted in an average 14\% greater reduction in plant height at all application rates (Fig. 1). A quantitative comparison of the relative effectiveness of the two methods of application was obtained by comparing the extrapolated values of incipient growth inhibition, i.e., the minimum concentration necessary to inhibit growth. This value can obtained by solving each regression equation for the concentration $(\mathrm{x})$ at which the height (y) equals the control value. The values for incipient growth inhibition were $1.46 \times 10^{-4}$ and $6.76 \times 10^{-5} \mathrm{~g} /$ pot for drench and foliar applied TE, respectively. Thus, plant height was sensitive to an approximate 2 -fold lower TE dose when foliar-applied than when drench-applied. This same relative effectiveness of the two methods was observed across all concentrations used in this experiment (Fig. 1 ) since the slopes of the two regressions lines were not significantly different $(P=0.05)$. Therefore foliar applications were used in all subsequent experiments.

There was no effect of TE on the number of nodes. No phytotoxicity was observed on plants treated with TE rates up to $1.0 \times 10^{-3} \mathrm{~g}$ /plant. Only slight phytotoxicity in the form of yellowing on the sprayed leaves was observed on plants treated with $2.0 \times 10^{-3} \mathrm{~g}$.

Cultivar response study. The effects of a single application of TE at two rates on the growth of various chrysanthemum cultivars are shown in Table 2. While TE at both rates reduced canopy height of all cultivars, there was considerable variation among the cultivars in the extent of the inhibition. The reduction in canopy height at 28 DAT ranged from $18 \%$ and $23 \%$ in 'White Graceland' to $1 \%$ and $7 \%$ in 'White Viewtime' following application of $5 \times 10^{-4}$ and $1 \times 10^{-3} \mathrm{~g}$ TE, respectively (Table 2 ). The growth suppressing effect of TE was not correlated with either height or flowering time. There was an interaction between TE rate and experiment (Table 2). Growth suppression in the first experiment, conducted in July, was

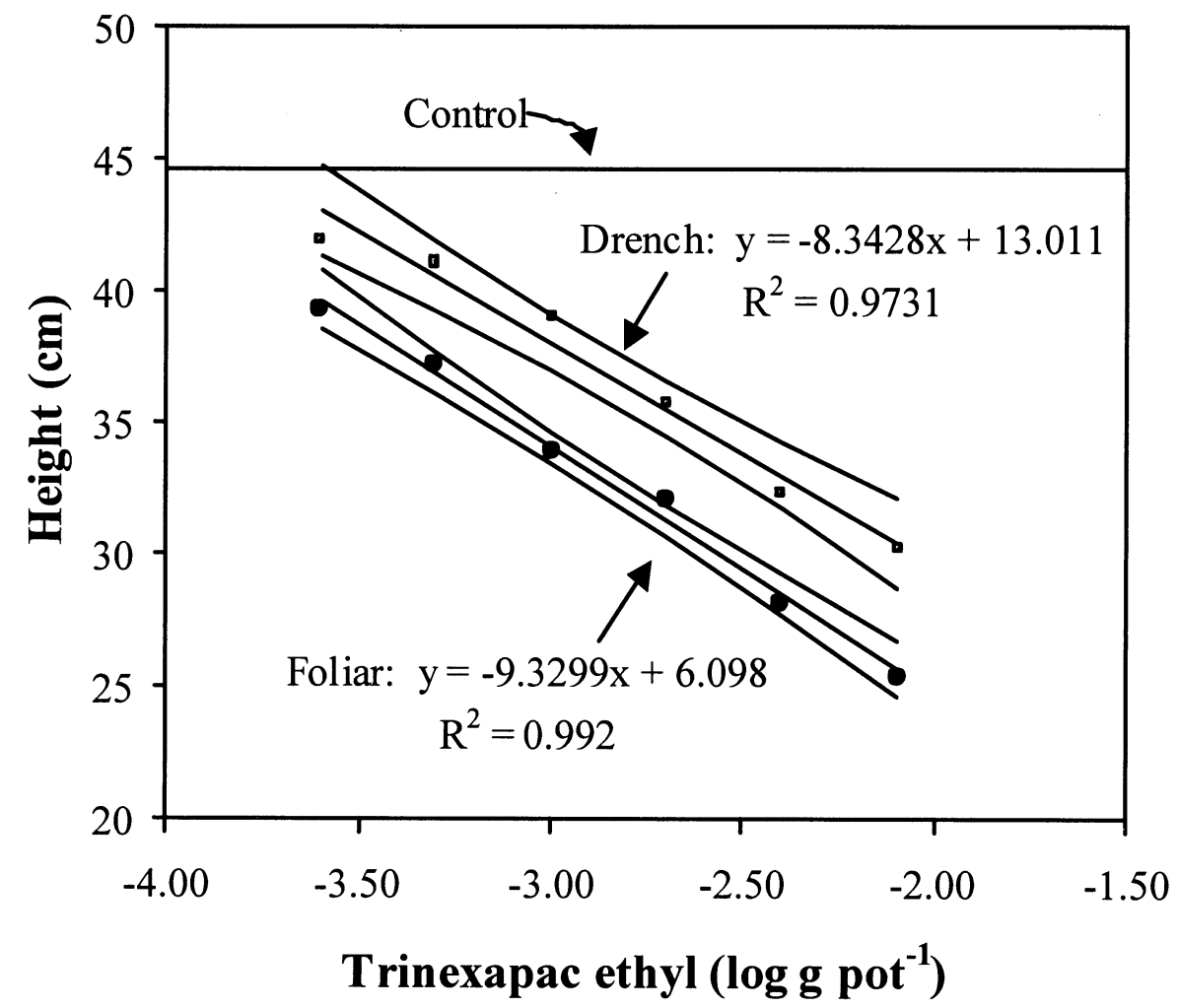

Fig. 1. Dose response and 95\% confidence intervals based on the regression of plant height of 'Billings' chrysanthemum on the log-transformed dose of trinexepac-ethyl (TE) applied directly to the plant foliage versus a soil drench in two greenhouse experiments. 
greater than for the second experiment, which was conducted in February. While statistically

significant, the differences were of no practical significance.

Table 2. The effect of TE applied at 2 concentrations on the height of plants of various chrysanthemum cultivars. Results are the means of two experiments conducted in a greenhouse in Columbus, Ohio beginning on 27 June 2002 and 18 February 2003.

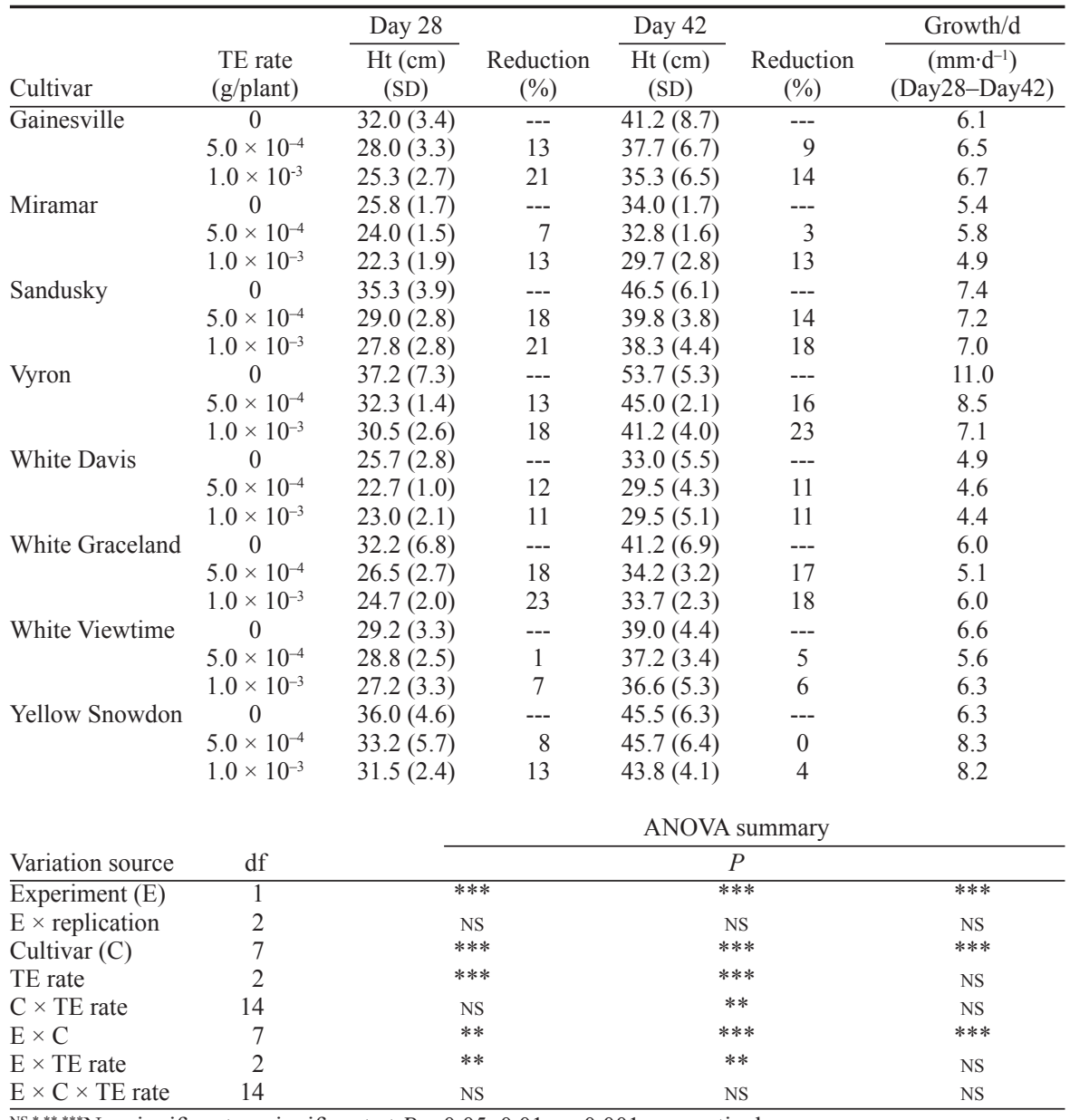

NS, ${ }^{* * *, * * * *}$ Nonsignificant or significant at $P<0.05,0.01$, or 0.001 , respectively.

Table 3. Comparison of the effect of one or two applications of TE at $5.0 \times 10^{-4} \mathrm{~g} / \mathrm{plant}$ on the height of plants of various chrysanthemum cultivars. Results are the means of two experiments conducted in a greenhouse in Columbus, Ohio, beginning on 6 Jan. and 21 Feb. 2003.

\begin{tabular}{|c|c|c|c|}
\hline Cultivar & Schedule & $\begin{array}{c}\mathrm{Ht}(\mathrm{cm}) \\
(\mathrm{SD})\end{array}$ & $\begin{array}{c}\text { Reduction } \\
(\%)\end{array}$ \\
\hline \multirow[t]{3}{*}{ Chesapeake } & 0 & $36.2(12.6)$ & --- \\
\hline & Week 1 & $34.7(11.0)$ & 4 \\
\hline & Weeks 1 and 5 & $30.8(8.3)$ & 15 \\
\hline \multirow[t]{3}{*}{ Surf } & 0 & $27.7(5.2)$ & --- \\
\hline & Week 1 & $25.7(5.5)$ & 7 \\
\hline & Weeks 1 and 5 & $24.8(5.0)$ & 10 \\
\hline \multirow[t]{3}{*}{ White Blush } & 0 & $33.7(7.0)$ & --- \\
\hline & Week 1 & $31.2(6.5)$ & 7 \\
\hline & Weeks 1 and 5 & $27.3(3.7)$ & 19 \\
\hline \multirow[t]{4}{*}{ Yellow Nob Hill } & 0 & $40.5(9.7)$ & --- \\
\hline & Week 1 & $39.2(9.1)$ & 3 \\
\hline & Weeks 1 and 5 & $32.5(3.4)$ & 20 \\
\hline & & $\begin{array}{l}\text { ANOVA } \\
\text { summary }\end{array}$ & \\
\hline Variation source & df & $P$ & \\
\hline Experiment (E) & 1 & $* * *$ & \\
\hline $\mathrm{E} \times$ replication $(\mathrm{R})$ & 2 & NS & \\
\hline Cultivar (C) & 3 & $* * *$ & \\
\hline Application schedule (AS) & 2 & $* * *$ & \\
\hline $\mathrm{C} \times \mathrm{AS}$ & 6 & $*$ & \\
\hline $\mathrm{E} \times \mathrm{C}$ & 3 & $* * *$ & \\
\hline $\mathrm{E} \times \mathrm{AS}$ & 2 & $* * *$ & \\
\hline $\mathrm{E} \times \mathrm{C} \times \mathrm{AS}$ & 6 & NS & \\
\hline
\end{tabular}

${\mathrm{NS},{ }^{*}, * *, * * *}^{*}$ Nonsignificant or significant at $P<0.05,0.01$, or 0.001 , respectively.
In the subsequent 2 weeks ( 28 to 42 DAT), the effect of TE on growth of most cultivars was diminished as evidenced by similar average daily growth rates between controls and the treatments and similar differences in canopy heights (Table 2). There were, however, two notable exceptions. For 'Vyron', slightly more inhibition in terms of both percent reduction in canopy height and average daily growth rates was observed in the last 2 weeks than the first 4. The other exception was 'Yellow Snowden' in which the percent reduction in canopy height at 42 DAT was less than at 28 DAT. This suggested, in contrast to the first 4 weeks, that growth rates of TE-treated 'Yellow Snowdon' plants were actually greater than control plants during the final 2 weeks of the experiment. Indeed, the average daily growth rates for the two treatments during the last 2 weeks of the experiment were about 2 $\mathrm{mm}$ greater than the control. In none of the cultivars were flowering times or total flower production affected by TE application.

Repeat application study. As in the cultivar response study, the inhibition of growth varied among cultivars from $3 \%$ to $20 \%$ (Table 3 ). In addition, once-treated plants of 'Surf' and 'White Blush' remained shorter than did plants of 'Chesapeake' and 'Yellow Nob Hill' at 63 DAT (Table 3).

A second application of TE at day 35 resulted in additional reduction in canopy heights of all cultivars when measured 4 weeks after the second TE application, although the additional growth suppression with the second TE application was relatively small for 'Surf" (Table 3 ). The second TE application also eliminated the post-suppression rebound in growth rates that were observed in once-treated plants of 'Yellow Nob Hill'.

In the first experiment, the day $35 \mathrm{TE}$ application was made to vegetative plants, while in the second experiment, the TE application was made to plants that had initiated flower buds. The day 35 application resulted in greater suppression of plants in the second experiment than in the first.

Effect on flowering study. Application of TE at bud set reduced canopy heights of 'Miramar' and 'Sandusky' by about $15 \%$ and $18 \%$, respectively (Table 4). The application at bud break did not result in a decrease in canopy height of 'Miramar' but there was a modest effect (9\%) on 'Sandusky' (Table 4). No differences in total flower yield, mean mass per flower, or flower color were observed due to TE application.

\section{Discussion}

We have shown that TE is an effective growth regulator of chrysanthemums. These data demonstrate that efficacy of TE was equal or superior to other growth regulators commonly used in commercial chrysanthemum production. We also have observed little or no growth regulating activity of TE in a variety of other species including american marigold (Tagetes erecta L.), begonia (Begonia semperflorens-cultorum hort.), impatien (Impatiens wallerana Hook.), petunia (Petunia $\times$ hybrida 
Table 4. The effect of TE applied at different stages of development on canopy height and flower yield of two chrysanthemum cultivars. Results are the means of two experiments conducted in separate greenhouses in Columbus, Ohio, beginning on 7 Jan. 2003.

\begin{tabular}{|c|c|c|c|c|}
\hline \multirow[b]{2}{*}{ Cultivar } & \multirow[b]{2}{*}{$\begin{array}{l}\text { Application } \\
\text { timing }\end{array}$} & \multirow[b]{2}{*}{$\begin{array}{c}\text { Canopy } \\
\text { ht (cm) } \\
\text { (SD) }\end{array}$} & \multicolumn{2}{|c|}{ Flower yield (g) } \\
\hline & & & $\begin{array}{l}\text { Total } \\
\text { yield } \\
(\mathrm{SD})\end{array}$ & $\begin{array}{c}\text { Mean } \\
\text { mass/ } \\
\text { flower } \\
\text { (SD) }\end{array}$ \\
\hline \multirow[t]{3}{*}{ Miramar } & Control & $37.2(2.2)$ & $71.4(25.0)$ & $5.1(0.3)$ \\
\hline & Bud set & $32.3(2.0)$ & $71.0(14.0)$ & $4.7(0.4)$ \\
\hline & Budbreak & $39.0(2.9)$ & $63.2(7.4)$ & $4.5(0.1)$ \\
\hline \multirow[t]{3}{*}{ Sandusky } & Control & $47.0(1.4)$ & $46.0(7.0)$ & $3.3(0.2)$ \\
\hline & Bud set & $39.5(2.3)$ & $51.0(4.8)$ & $3.0(0.1)$ \\
\hline & Budbreak & $43.0(1.4)$ & $54.1(6.2)$ & $3.1(0.3)$ \\
\hline
\end{tabular}

\begin{tabular}{|c|c|c|c|c|}
\hline \multirow[b]{2}{*}{ Variation source } & \multirow[b]{2}{*}{ df } & \multicolumn{3}{|c|}{ ANOVA summary } \\
\hline & & & $P$ & \\
\hline Experiment (E) & 1 & NS & NS & NS \\
\hline $\mathrm{E} \times$ replication $(\mathrm{R})$ & 2 & NS & NS & NS \\
\hline Cultivar (C) & 1 & $* * *$ & * & $* * *$ \\
\hline Application schedule (AS) & 2 & $* * *$ & NS & NS \\
\hline $\mathrm{C} \times \mathrm{AS}$ & 2 & $* *$ & NS & NS \\
\hline $\mathrm{E} \times \mathrm{C}$ & 1 & NS & NS & NS \\
\hline $\mathrm{E} \times \mathrm{AS}$ & 2 & NS & NS & NS \\
\hline $\mathrm{E} \times \mathrm{C} \times \mathrm{AS}$ & 2 & NS & NS & NS \\
\hline
\end{tabular}

NS,********Nonsignificant or significant at $P<0.05,0.01$, or 0.001 , respectively.

Hook.), tomato, (Lycopersicon esculentum Mill.), and pepper (Capsium annuum L.) (D.S. Gardner and J.D. Metzger, unpublished observations). Previous workers have reported that while acyclohexanediones such as TE and prohexadione-Ca are effective growth regulators for many members of the Poaceae including turf species, TE is typically less active than procyclohexadione-Ca in dicots (Rademacher, 2000). Thus, the sensitivity of chrysanthemum to TE appears to be an exception. Rademacher (2000) has speculated that the reduced activity of TE in dicots is based on the relative inability to hydrolyze the ethyl ester into the active acid form as compared to Poaceae species. If this is so, then it would appear that chrysanthemum, and perhaps related species, are exceptional among dicots in the ability to effectively hydrolyze TE into the active acid form.

TE exhibited growth-regulating activity when applied either as foliar spray or a root drench, although the former was about twice as effective as the latter (Fig. 1). This contrasts with growth regulators currently used for chrysanthemums. Both paclobutrazol and uniconazol are predominantly translocated acropetally, and therefore are relatively ineffective when applied as foliar sprays; these compounds are applied either as a drench or a spray to the stems. On the other hand, daminozide, which is the most commonly used chemical growth regulator in chrysanthemums, must be applied as a foliar spray (Higgins, 2001). Therefore a potential advantage of TE is flexibility of application method to fit the specific growth stage of the crop and/or needs of the grower.

There were cultivar and time of year differences in the response to TE. However there was no clear-cut relationship between the amount of growth inhibition and the growthtype of the cultivar, i.e., whether the cultivar was classified as tall, medium, etc. (Table 2). This may be attributed to the fact that growth is controlled by multiple interacting systems. For example in chrysanthemum, the inhibition of stem growth by red light and by GA biosynthesis inhibitors is not mediated by the same mechanism (Zheng et al., 2001). Alternatively, there may be differences in the response of the target enzymes in the GA biosynthesis pathway, or there may be variation in the rates of degradation/inactivation of TE.

Trinexapac-ethyl and the related PGR prohexadione-Ca are reported to have relatively short half-lives in plant tissues and soils, especially when compared to compounds such as paclobutrazol and uniconazol (Rademacher, 2000). Our results are consistent with those observations. For most cultivars growth inhibition diminished after TE application such that by 4 weeks, growth rates of treated plants were about the same as the controls (Table 2). More complete growth control was obtained by multiple applications (Table 3), or by delaying the timing of the application to bud set (Table 4). The rapid inactivation of TE is a potential advantage in crop production since it may enhance growers' ability to fine tune growth regulation to suit changing conditions such as light intensity or temperature.

While the growth rates of most cultivars returned to control rates 4 to 6 weeks after application, one cultivar ('Yellow Snowdon') exhibited higher growth rates than the control. This post-suppression rebound effect has been observed in TE-treated turfgrass (Lickfeldt et al., 2001). However, neither the physiological mechanism, nor the implications for long-term use on turfgrass have been established (Fagerness and Yeleverton, 2000).

An even more extreme example of the postsuppression rebound phenomenon was observed in stock (Matthiola incana L.), which is a member of the Brassicaceae family. Application of either TE or prohexadione-Ca resulted in an increase in plant height in a dose-dependent manner. More remarkable was the observation that at certain temperature regimes, both growth retardants were more effective than exogenous $\mathrm{GA}_{4}$ (Hisamatsu, et al., 1998). The authors' explanation is based on the observation that the acyclohexanedione growth retardants inhibit the enzymes that hydroxylate gibberellins at both the $2 \beta$ and $3 \beta$ positions of the ent-gibberellane skeleton (Rademacher, 2000). Hydroxylation at the $3 \beta$ position is require for maximum activity, while $2 \beta$ hydroxylation is the main biochemical deactivation mechanism in gibberellin metabolism (Hedden and Kamiya, 1997). It may be that in stock, the $3 \beta$-hydroxylase is relatively insensitive to the acyclohexanediones compared to the $2 \beta$-hydroxylase. In such a scenario, highly active $3 \beta$ hydroxylated gibberellins such as $\mathrm{GA}_{4}$ or $\mathrm{GA}_{1}$ may accumulate because their inactivation via $2 \beta$ hydroxylation is greatly reduced due to inhibition of the $2 \beta$ hydroxylase by the two acyclohexanediones (Hisamatsu et al., 1998). There may be similar basis for the post-suppression rebound effect we observed (Table 2). Following application of TE, the activity of the $3 \beta$-hydroxylase may be severely inhibited resulting in a reduction in the synthesis of biologically active gibberellins and, as a consequence, decreased growth rates. If the chrysanthemum $2 \beta$-hydroxylase is more sensitive to TE than the $3 \beta$-hydroxylase, one may expect that as the plant progressively deactivates TE, biologically active gibberellins accumulate because of a lower $2 \beta$-hydroxylase activity relative to the $3 \beta$-hydroxylase.

In addition to inhibiting stem growth, there are reports that acyclohexanediones at high concentrations produce novel nonlethal side effects. For example at high rates there is a reduction of anthocyanin synthesis in different plant organs, including flowers, probably by inhibiting the 2-oxoglutarate-dependent enzymes in the biosynthetic pathway such as flavanone 3-hydroxylase (Ilan and Dougall, 1992; Rademacher et al., 1992). We did not observe any indication of a reduction in anthocyanin synthesis in the flowers, even when high doses of TE were applied at either bud set or bud break (data not shown). We observed little phytotoxicity even at the highest doses of TE. Only slight phytotoxicity in the form of chlorosis on the sprayed leaves was observed on plants treated with $2.0 \times 10^{-3} \mathrm{~g}$ or $4.0 \times 10^{-3}$ g per plant which may be attributable to the surfactants and or adjuvants in the Primo 1EC formulation. Similar phytotoxicity has been observed in turfgrass (Fagerness and Yelverton, 2000). As with turfgrass, subsequent growth did not show symptoms, and chlorosis was undetectable after 2 to 4 weeks.

\section{Conclusions}

Based on the results of these studies, trinexapac-ethyl may be a useful growth regulator for the production of chrysanthemums. There are several potential advantages to TE use, including predictable dose-dependent response, almost no phytotoxicity, and relatively short duration of effectiveness. On plants that were induced to flower immediately, two applications 4 weeks apart provided better height suppression than a single application. However, 
best growth control was achieved when TE was applied immediately after initiation of flower buds.

\section{Literature Cited}

Daniels, R.W. and S.K. Sugden, 1996. Opportunities for growth regulation of amenity grass. Pest. Sci. 47:363-369.

Fagerness, M.J. and D. Penner. 1998. Evaluation of V-10029 and trinexapac-ethyl for annual bluegrass seedhead suppression and growth inhibition in five cool-season species. Weed Technol. 12:436-440.

Fagerness, M.J. and F.H. Yelverton. 2000. Tissue production and quality of 'Tifway' bermudagrass as affected by seasonal application patterns of trinexapac-ethyl. Crop Sci. 40:493-497.

Hedden, P. and Y. Kamiya. 1997. Gibberellin biosynthesis: enzymes, genes, and their regula- tion. Annu. Rev. Plant Physiol. Plant Mol. Biol. 48:431-460

Hisamatsu, T., M. Koshioka, S. Satoshi, and R.W. King. 1998. Effect of gibberellin $\mathrm{A}_{4}$ and GA biosynthesis inhibitors on growth and flowering of stock [Matthiola incana (L.) R. Br.]. J. Japan. Soc. Hort. Sci. 67:537-543.

Higgins, E. 2001. Chrysanthemums, p, 68-70. In: M.L. Gaston, L.A. Kunkle, M.F. Witt, and P.S. Konjoian (eds.). Tips on regulating growth of floriculture crops. OFA Services, Inc., Columbus, Ohio.

Ilan, A. and D.K. Dougall. 1992. The effect of growth retardants on anthocyanin production in carrot cell suspension cultures. Plant Cell. Rpt. 11:304-309.

Lickfeldt, D.W., D.S. Gardner, B.E. Branham, and T.B. Voigt. 2001. Implications of repeated trinexapac-ethyl applications on kentucky bluegrass. Agron J. 93:1164-1168.
Nelson, P.V. 1998. Greenhouse operation and management. 5th ed. Prentice Hall, Upper Saddle River, N.J.

Rademacher, W. 2000. Growth retardants: Effects on gibberellin biosynthesis and other pathways. Annu. Rev. Plant Physiol. Plant Mol. Biol. 51: 501-531.

Rademacher, W., K.E. Temple-Smith, D.L. Griggs, and P. Hedden. 1992. The mode of action of acylcyclohexanediones-a new type of plant growth retardant, p, 571-577. In: C.M. Karssen, L.C. van Loon, and D. Vreugdenhil(eds.). Progress in plant growth regulation. Kluwer, Dordrecht.

SAS Institute. 1990. SAS/STAT user's guide. vol. 2. 4th ed. SAS Institute, Cary, N.C.

Zheng, Z.L., Z. Yang, J.C. Jang, and J.D. Metzger. 2001. Modification of plant architecture in chrysanthemum by ectopic expression of the tobacco phytochrome $B 1$ gene. J. Amer. Soc. Hort. Sci. 126:19-26. 